\title{
Usefulness of serum procalcitonin as a diagnostic biomarker of infection in children with chronic kidney disease
}

\author{
Fatina I. Fadel ${ }^{1}$, Manal F. Elshamaa ${ }^{2}$, Eman A. Elghoroury ${ }^{3}$, Ahmed M. Badr ${ }^{1}$, Solaf Kamel ${ }^{3}$, \\ Marwa M. El-Sonbaty ${ }^{4,5}$, Mona Raafat ${ }^{3}$, Hebatallh Farouk ${ }^{3}$
}

\author{
${ }^{1}$ Pediatrics Department, Faculty of Medicine, Cairo University, Cairo, Egypt \\ ${ }^{2}$ Pediatrics Department, National Research Centre, Cairo, Egypt \\ ${ }^{3}$ Clinical and Chemical Pathology Department, National Research Centre, Cairo, Egypt \\ ${ }^{4}$ Department of Child Health, National Research Centre, Cairo, Egypt \\ ${ }^{5}$ Department of Pediatrics, College of Medicine, Taibah University, Al- Madinah \\ Al- Munawwarah, Kingdom of Saudi Arabia
}

Submitted: 8 March 2016

Accepted: 9 April 2016

Arch Med Sci Atheroscler Dis 2016; 1: e23-e31

DOI: 10.5114/amsad.2016.59672

Copyright (C) 2016 Termedia \& Banach

\section{Abstract}

Introduction: Serum procalcitonin (PCT) levels are known to be low in healthy individuals in healthy subjects but are increased in patients with a severe bacterial infection. It has not been extensively studied in children with chronic kidney disease (CKD), treated either with hemodialysis (HD) or with renal transplantation.

Material and methods: During a 6-month period, blood samples were taken from 102 (55 HD children and 47 renal transplant recipients) children with a strong clinical suspicion of infection. Procalcitonin levels were measured by ELISA.

Results: Thirty-four/102 cases had proven infections as defined previously. Children with proven infections had a significantly higher PCT $(0.920$ $\pm 0.24 \mathrm{ng} / \mathrm{ml})$ than those without $(0.456 \pm 0.53 \mathrm{ng} / \mathrm{ml}), p=0.04$. The ideal cutoff value derived for serum PCT was $0.5 \mathrm{ng} / \mathrm{ml}$. This threshold value established a sensitivity of $94.1 \%$ and a specificity of $87.9 \%$.

Conclusions: This study indicates that significantly increased PCT concentration is a promising predictor of systemic bacterial infection in children with CKD, with good sensitivity and specificity. This study proposes that serum PCT is a convenient index of infection in CKD children at a cutoff value of $0.5 \mathrm{ng} / \mathrm{ml}$.

Key words: chronic kidney disease, children, infection, procalcitonin, cutoff value, hemodialysis, transplantation.

\section{Introduction}

Chronic kidney disease (CKD) is a significant public health dilemma [1] with an advanced requirement for dialysis either hemodialysis (HD) or peritoneal dialysis every year. The increased risk of infection in CKD patients has been demonstrated [2, 3], especially in those treated with chronic HD [4]. Risk markers that possibly mark this susceptibility to infection are plentiful, including [5-8] coexisting illnesses such as immunosuppressive therapy for the underlying kidney disease, uremia-induced leukocyte dysfunction, vaccine hyporesponsiveness, malnutrition, bloodstream infections_fundamentally concerning vascular (fistula or catheters) access
Corresponding author: Prof. Dr Manal F. Elshamaa Pediatric Department National Research Centre 33 Elbohous St

12311 Dokki, Cairo, Egypt Phone: +20 233371010 Fax: +20 237601877 E-mail: manal_elshmaa@ hotmail.com 
$[8,9]$ and hemodialysis with frequent disturbance of the skin barrier. For all these reasons, CKD may be considered as a condition of acquired immunodeficiency [6]. Moreover, it has been reported that at the moment infection, CKD patients had a much greater risk of mortality than healthy individuals $[9,10]$, due to which infection is the second main cause of mortality after cardiovascular diseases [4]. Furthermore, infectious disease is a leading reason for intensive care unit (ICU) admittance and accounts for $15 \%$ to $25 \%$ of overall ICU admittance in CKD patients [11-15].

Clinical and laboratory signs of systemic infection, including hypo/or hyperthermia, apnea or tachypnea, tachycardia and increased white blood cell counts, are critical. However, their application is restricted by inferior specificity and peculiarity for the diagnosis of sepsis, as seriously sick patients often have the systemic inflammatory response syndrome (SIRS) but no infection [16-18]. Some inflammatory parameters, such as leukocyte cell count, cytokines (TNF- $\alpha$, IL-1 $\beta$, or IL- 6 ) and C-reactive protein (CRP), have been applied for the diagnosis of infection and inflammation, but their deficiency of specificity has drawn attention to the need for more specific laboratory investigations [19, 20].

Procalcitonin (PCT), the precursor protein of calcitonin, is a polypeptide of 116 amino acids (MW $13 \mathrm{kDa}$ ) which has been reported to be able to accurately distinguish bacterial from nonbacterial infections and other inflammation conditions [21, 22].

In contrast to C-reactive protein, PCT secretion is inhibited by interferon $\gamma($ IFN- $\gamma$ ), a cytokine which is manufactured during viral infections. It has been confirmed as helpful in distinguishing complications due to bacterial infections [22-24]. Serum PCT level is rising at 3 to $6 \mathrm{~h}$ following bacterial infection, but is not in autoimmune disease, non-infectious inflammatory responses, local infection, viral infection or sepsis. So, it might seem that PCT measurement has the ability to raise the certainty of the diagnosis of a bacterial infection greater than measuring other infection parameters, such as leukocyte counts or CRP [25].

Procalcitonin has not been widely studied in children with ESRD or renal transplant (RTx). The scarce presently obtainable studies are either comparatively small in sample size or use unrepresentative individuals [26-29]. Therefore, the comparative advantage of PCT testing in children with chronic kidney disease is not certain.

The present study aimed to identify early biological predictors of infection by determining the diagnostic significance of PCT in comparison to other traditional inflammatory factors in a considerable CKD children group, applying principles for the definitions of systemic infections and to determine an appropriate cutoff level.

\section{Material and methods}

\section{Inclusion criteria}

One hundred and two consecutive children (with suspected infection detected initially by clinical symptoms) were included in this retrospective (case-control) study during a 6-month period. All patients were treated in the Center of Pediatric Nephrology and Transplantation (CPNT), Children Hospital, Cairo University, Cairo, Egypt. Informed consent was taken from the parents of each participant. The study protocol was approved by the Ethics Committee of the National Research Center (NRC) in Egypt.

\section{Hemodialysis children}

The patients were routinely hemodialyzed three times per week in sessions lasting $4 \mathrm{~h}$ using polysulfone dialyzer membrane. The dialysate flow rate was $500 \mathrm{ml} / \mathrm{min}$, blood flow rates ranged from 80 to $200 \mathrm{ml} / \mathrm{min}$, and the ultrafiltration rate was between 300 and 1,000 ml/h. Each patient was treated with heparin just prior to the start of HD. The water treatment system consisted of simple reverse osmosis, disinfected weekly. According to the guidelines of the American Association of Medical Instruments and the European Pharmacopoeia, appropriate laboratory methods were chosen to detect bacteria (upper limit for bacterial growth $<100 \mathrm{CFU} / \mathrm{ml}$ in the dialysate) and endotoxins (upper limit $0.25 \mathrm{EU} /$ $\mathrm{ml}$ ) and other bacteria-derived substances (whole-blood cytokine induction assay). Vascular access (VA) was via arteriovenous (AV) fistulas $(n=44)$ and a tunneled permanent catheter (TPC) $(n=11)$.

\section{Transplant children}

Transplantation was performed in $46.1 \%$ of cases from living donors. All children received intravenous methylprednisolone (12.5-30 mg/ day) in the first month of transplantation, and then oral prednisolone was tapered down to 2.5-7.5 mg/day in the first year of transplantation. The renal transplant patients received an immuno-suppressive regimen including a calcineurin inhibitor, mycophenolic acid (MMF), and mammalian target of rapamycin (mTOR). In transplant cases with increased PCT, cytomegalovirus and polyoma BK virus infections were ruled out if the copy number by real-time polymerase chain reaction (RT-PCR) was less than 2,000 copies $/ \mathrm{ml}$ or with tissue biopsy.

Healthy control subjects having no history or clinical signs of renal, cardiac, cerebrovascular vascular disease or infectious disease were recruited from the Pediatric Clinic of NRC. 


\section{Infection definition}

The definition of infection was standardized using criteria stated by the Centers for Disease Control and Prevention and included bloodstream, pulmonary or intra-abdominal infections detected by radiological findings, clinical symptoms, and proven by micro-biological tests. Clinical symptoms of infection included a combination of any of the following parameters: a temperature less than $36^{\circ} \mathrm{C}$ or greater than $38^{\circ} \mathrm{C}$, chills, or purulent sputum or urine. Chest $\mathrm{X}$-rays, ultrasound examinations, or computed tomography scans were recommended when a clinically based infection was suspected, and on the basis of these examinations, prompt therapy was started. Samples from the suspected site of infection (e.g. urine, blood, or catheter tips) were taken and cultured. According to the 2001 Society of Critical Care Medicine/European Society of Critical Care Medicine/American College of Chest Physicians/American Thoracic Society/Surgical Infection Society criteria, sepsis was defined by the occurrence of infection and SIRS [30].

\section{Definition of infection as per principles}

Community-acquired pneumonia (CAP) and urinary tract infection are acute illnesses as defined previously [31, 32]. Enterocolitis was detected through diarrheal syndrome [33]. Arterial-venous fistula infections were defined by clinical inflammatory presentation and/or positive blood culture.

\section{Peripheral blood sampling}

A peripheral blood sample was obtained pre-dialysis from the hemodialysis children, transplant recipients (after transplantation) and healthy controls. Immediate centrifugation was done for $10 \mathrm{~min}$ at $5000 \mathrm{rpm}$ at $4^{\circ} \mathrm{C}$. The centrifuged serum was transferred into sterile tubes. All samples were stored at $-70^{\circ} \mathrm{C}$ until assay.

\section{Investigated laboratory parameters}

Procalcitonin was measured using the PCT ELISA assay (Bio Vendor R\&D, Germany). The normal range was defined as $0-0.2 \mathrm{ng} / \mathrm{ml}$. For the analysis, we used two different cutoff values: (1) $0.5 \mathrm{ng} / \mathrm{ml}$, (2) $0.75 \mathrm{ng} / \mathrm{ml}$. High-sensitivity CRP (hsCRP) was determined by the solid phase chemiluminescent immunometric assay (Immulite/Immulite 1000) (supplied by SIEMENS Medical Solution Diagnostics). Biochemical laboratory parameters were measured by an automatic biochemistry analyzer.

\section{Statistical analysis}

Statistical Package for the Social Sciences (SPSS) program version 16.0 was used for analysis of data. Data were summarized as mean \pm
$\mathrm{SD}$, range or percentage. Histograms and normality plots were used for evaluating the normality of data. For those data with skewed distribution, log transformation was performed before a $t$-test. Data were evaluated between the experimental groups by an independent $t$-test or Pearson $\chi^{2}$ test. Sensitivity, specificity, predictive values of PCT, CRP, and white blood cells (WBC) were calculated from data of the entire cohort and by subgroups. The diagnostic accuracy of the biomarkers for diagnosis of infection was expressed as the area under the corresponding receiver operating characteristic curve (AUROC), and the respective areas under the curves were calculated with 95\% confidence intervals. The different AUROCs were compared using the method described by Hanley and McNeil [34]. We used the Youden index to find the optimal threshold point from the ROC curve. Pearson's analysis was performed to correlate between PCT and different variables. A $p$-value of $<0.05$ was considered statistically significant.

\section{Results}

\section{Patients}

The study group consisted of 102 children (age 2-20 years, 48 females) divided into two subgroups: 34 patients with proven infection and 68 without proven infection.

Fifty-five were on HD and 47 were RTx recipients. General characteristics of the retrospective study groups are shown in Table I. Children with proven infection had a lower erythropoietin requirement and a lower percentage of patients on dialysis (Table II). The main comorbidities of the studied CKD children were cardiovascular disease (22.55\%) and viral infections (20.59\%).

\section{Infectious state}

During the study period, 34/102 children had proven infections according to infection definitions with the following breakdown: 15 children with vascular access infections (44.11\%), 11 with pyelonephritis (32.35\%), 4 with pneumonia $(11.77 \%)$, and 4 with enterocolitis (11.77\%). Six of the 34 children studied with proven infections were diagnosed with sepsis (2 children on $\mathrm{HD}$, and 4 transplanted recipients) in the form of pneumonia (1), pyelonephritis (3), enterocolitis (1), and AV fistula infection (1).

\section{Procalcitonin values}

Procalcitonin levels were increased $(>0.5 \mathrm{ng} / \mathrm{ml})$ in $64.71 \%$ of the patients $(66 / 102)$, with a mean \pm SD of $0.814 \pm 0.46 \mathrm{ng} / \mathrm{ml}$. These levels were significantly higher than in controls $(0.145 \pm 0.09$, $p=0.0001)$. Children with proven infections had 
Table I. Baselines characteristics of studied groups

\begin{tabular}{|c|c|c|c|}
\hline Parameter & $\begin{array}{l}\text { All patients } \\
\quad(n=102)\end{array}$ & $\begin{array}{l}\text { Controls } \\
(n=20)\end{array}$ & $P$-value \\
\hline Age [years] & $10.86 \pm 3.81$ & $10.00 \pm 8.80$ & 0.66 \\
\hline Gender (M/F) & $54(52.94 \%) / 48(47.06 \%)$ & $12(60 \%) / 8(40 \%)$ & 0.31 \\
\hline $\mathrm{BMI}\left[\mathrm{kg} / \mathrm{m}^{2}\right]$ & $21.76 \pm 7.21$ & $22.88 \pm 7.50$ & 0.27 \\
\hline Renal replacement (dialysis, \%) & $55(53.40 \%)$ & & \\
\hline Erythropoietin requirement [IU/W] & $4214.30 \pm 1652.75$ & & \\
\hline $\mathrm{SBP}[\mathrm{mm} \mathrm{Hg}]$ & $115.11 \pm 14.26$ & $94.55 \pm 9.80$ & 0.03 \\
\hline $\mathrm{DBP}[\mathrm{mm} \mathrm{Hg}]$ & $73.98 \pm 9.68$ & $60.59 \pm 10.11$ & 0.62 \\
\hline Albumin $[\mathrm{g} / \mathrm{dl}]$ & $3.72 \pm 0.53$ & $4.92 \pm 0.39$ & 0.06 \\
\hline Hemoglobin $[\mathrm{g} / \mathrm{dl}]$ & $10.52 \pm 1.70$ & $14.20 \pm 1.50$ & 0.27 \\
\hline $\mathrm{WBC}\left[\times 10^{3} / \mathrm{mm}^{-3}\right]$ & $6.94 \pm 2.57$ & $3.57 \pm 1.42$ & 0.002 \\
\hline $\mathrm{PCT}[\mathrm{ng} / \mathrm{ml}]$ & $0.814 \pm 0.46$ & $0.145 \pm 0.09$ & 0.0001 \\
\hline
\end{tabular}

Values were presented as means $\pm S D$ or percentage as applicable, $B M I-$ body mass index, SBP - systolic blood pressure, DBP - diastolic blood pressure, $W B C-$ white blood cells, $P C T$ - procalcitonin. $P<0.5$ was considered significant.

Table II. Baseline characteristics of patients with and without proven infection

\begin{tabular}{|lccc|}
\hline Parameter & $\begin{array}{c}\text { Confirmed infection } \\
(n=34)\end{array}$ & $\begin{array}{c}\text { Without confirmed infection } \\
(n=68)\end{array}$ & $P$-value \\
\hline Age $[$ years] & $10.41 \pm 4.21$ & $11.09 \pm 3.59$ & 0.40 \\
\hline Gender $(\mathrm{M} / \mathrm{F})$ & $7 / 9$ & $22.33 \pm 7.98$ & 0.90 \\
\hline BMI $\left[\mathrm{kg} / \mathrm{m}^{2}\right]$ & $20.89 \pm 6.04$ & $40(57.97 \%)$ & 0.57 \\
\hline Renal replacement (dialysis, \%) & $16(47.01 \%)$ & 0.04 \\
\hline Erythropoietin requirement $[\mathrm{IU} / \mathrm{W}]$ & $3695.7 \pm 1240.78$ & $118.5 \pm 1795.61$ & 0.05 \\
\hline SBP $[\mathrm{mmHg}]$ & $111.88 \pm 12.03$ & $74.26 \pm 10.08$ & 0.11 \\
\hline DBP $[\mathrm{mm} \mathrm{Hg]}$ & $73.44 \pm 9.02$ & $3.74 \pm 0.46$ & 0.69 \\
\hline Albumin $[\mathrm{g} / \mathrm{dl}]$ & $3.68 \pm 0.64$ & $10.50 \pm 1.50$ & 0.62 \\
\hline Hemoglobin $[\mathrm{g} / \mathrm{dl}]$ & $10.55 \pm 2.04$ & $6.83 \pm 2.49$ & 0.89 \\
\hline WBC $\left[\times 10^{3} / \mathrm{mm}^{-3}\right]$ & $7.16 \pm 2.76$ & $0.456 \pm 0.53$ & 0.55 \\
\hline PCT $[\mathrm{ng} / \mathrm{ml}]$ & $0.920 \pm 0.24$ & 0.04 \\
\hline
\end{tabular}

Values are presented as means $\pm S D$ or percentage as applicable, $B M I-$ body mass index, $S B P$ - systolic blood pressure, DBP - diastolic blood pressure, $W B C-$ white blood cells, $P C T$ - procalcitonin. $P<0.5$ was considered significant.

a higher concentration of PCT $(0.920 \pm 0.24 \mathrm{ng} / \mathrm{ml}) \quad$ Overall, for a cutoff level of $0.5 \mathrm{ng} / \mathrm{ml}$, the sensitivthan those without $(0.456 \pm 0.53 \mathrm{ng} / \mathrm{ml}), p=0.04$. ity of the trial was $94.1 \%$ and the specificity $87.9 \%$,

The diagnostic achievement of PCT at various while using a cutoff level of $0.75 \mathrm{ng} / \mathrm{ml}$, as expectcutoff levels is shown in Figure 1 and Table III. ed, decreased its sensitivity by $11.7 \%$ and specific-

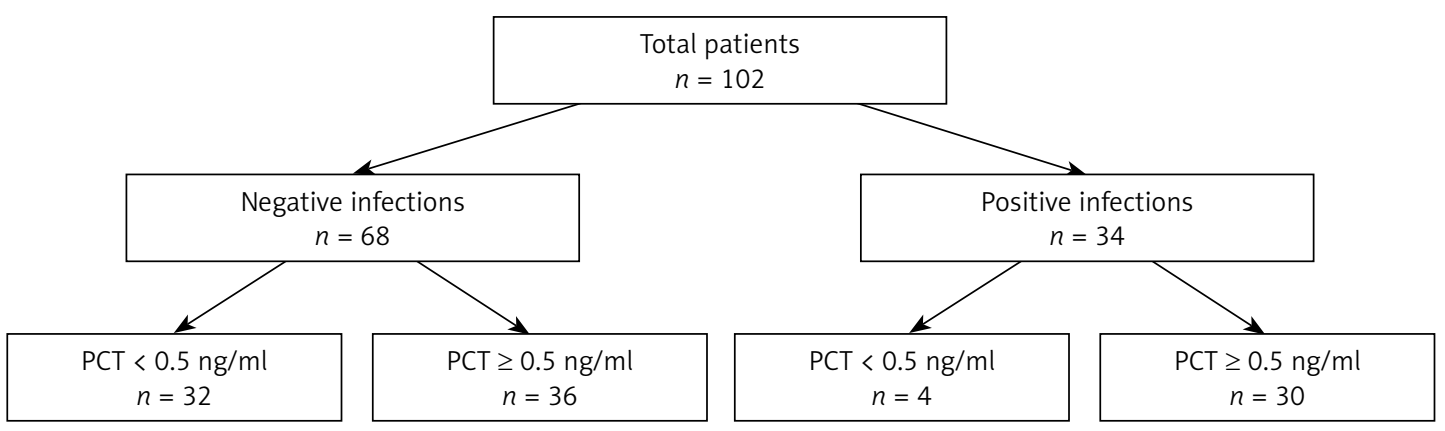

Figure 1. Diagram of diagnostic performance of serum PCT levels 
Table III. Analysis of procalcitonin at various cutoff levels $(n=102)$

\begin{tabular}{|lcccccccccccc|}
\hline PCT & \multicolumn{3}{c}{ Sensitivity (\%) } & \multicolumn{4}{c}{ Specificity (\%) } & \multicolumn{3}{c|}{$\begin{array}{c}\text { Positive predictive } \\
\text { value (\%) }\end{array}$} & \multicolumn{4}{c|}{$\begin{array}{c}\text { Negative predictive } \\
\text { value (\%) }\end{array}$} \\
\cline { 2 - 14 } & All & D & RTx & All & D & RTx & All & D & RTx & All & D & RTx \\
\hline$>0.5 \mathrm{ng} / \mathrm{ml}$ & 94.1 & 80 & 94.1 & 87.9 & 14.3 & 96.8 & 52.8 & 86.1 & 50.3 & 47.8 & 14.9 & 50.2 \\
\hline$>0.75 \mathrm{pg} / \mathrm{ml}$ & 82.4 & 73.3 & 76.5 & 66.7 & 2.9 & 74.2 & 56.4 & 97.5 & 51.9 & 44.3 & 0.04 & 48.8 \\
\hline
\end{tabular}

$D$ - dialysis, $R T x-$ renal transplant, $P C T$ - procalcitonin.

ity by $21.2 \%$. The best thresholds for the diagnosis of infection by PCT (ROC analysis - Youden index) were $0.441 \mathrm{ng} / \mathrm{ml}$ (sensitivity $94.1 \%$, specificity $93.9 \%)$. Also, when using the same method, we gained different cutoff levels in HD $(0.381 \mathrm{ng} / \mathrm{ml})$ and transplanted children $(0.529 \mathrm{ng} / \mathrm{ml})$.

\section{High-sensitivity CRP values}

High-sensitivity CRP was tested in only 50 children. Mean CRP serum concentration was 4.61 $\pm 5.24 \mathrm{mg} / \mathrm{l}$, with levels over the pre-specified cutoff (> $3 \mathrm{mg} / \mathrm{l}$ ) detected in $36 / 50$ children (72\%). These levels were significantly higher than in controls $(0.77$ $\pm 0.63, p=0.04$ ). Patients with proven infections had higher levels of CRP than those without proven infections (7.81 \pm 6.17 vs. $2.23 \pm 2.60, p=0.0001$ ).

For comparison of the overall performance of the infectious biomarkers independently of the pre-specified threshold levels, we tested the comprehensive degree of test performance using the AUROC. The ROC curves are shown in Figure 2 and Table IV. We found a significant difference in AUROC $(p=0.03, z$ statistic $=2.151,95 \% \mathrm{Cl}: 0.022-0.472)$ for PCT $(0.804,95 \% \mathrm{Cl}: 0.691-0.918, p=0.0001)$ compared to $\operatorname{WBC}(0.557,95 \% \mathrm{Cl}: 0.411-0.704$, $p=0.43)$, but no significant difference in AUROC ( $p=0.85$, $z$ statistic $=-0.1875,95 \% \mathrm{Cl}: 0.2061-$ $0.1701)$ for PCT $(0.833,95 \% \mathrm{Cl}: 0.736-0.931)$ in comparison to CRP $(0.835,95 \% \mathrm{Cl}: 0.730-0.940)$ - see Figure 2 and Table IV.

\section{Sub-relationship between PCT and CRP}

The sensitivity, specificity, and positive and negative predictive values for PCT and CRP in this subgroup of CKD children are shown in Table V. To compare the overall performance of the threshold

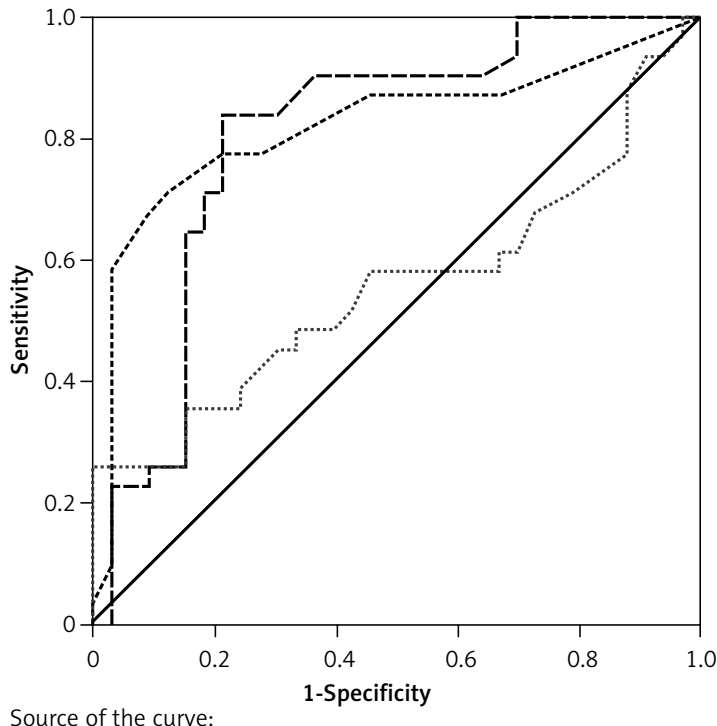

the curve:

-ーー PCT -.... CRP

Figure 2. ROC curve for determining area under the curve for PCT, hs-CRP, and total leukocytic count

effects of the two biomarkers independently of the threshold effects, we calculated the global measure of test achievements, area under the ROC. We did not find a significant difference in AUROC $(p=0.97, z$ statistic $=-0.0437,95 \% \mathrm{Cl}: 0.1755-$ $0.1835)$ for PCT $(0.832,95 \% \mathrm{Cl}: 0.733-0.931)$ in comparison to $\operatorname{CRP}(0.836,95 \% \mathrm{Cl}: 0.731-0.940)$.

\section{Correlation between PCT and both WBC and CRP}

Of the markers that had a significant difference in the groups with and without proven infections, WBC and CRP had positive correlations with serum PCT $(r=0.30, p=0.004$ and $r=0.44$, $p=0.000$, respectively) (Figure 3 ).

Table IV. Values of area under the curve for PCT, hs-CRP, and WBC

\begin{tabular}{|lccccc|}
\hline Parameter & Area & SE & Asymptomatic & Asymptomatic 95\% Cl \\
& & & sig. & Lower bound & Upper bound \\
\hline PCT & 0.804 & 0.058 & 0.000 & 0.691 & 0.918 \\
\hline Hs-CRP & 0.822 & 0.057 & 0.000 & 0.710 & 0.934 \\
\hline WBC & 0.557 & 0.075 & 0.43 & 0.411 & 0.704 \\
\hline PCT - procalcitonin, hs-CRP-high-sensitivity C-reactive protein, $W B C-$ white blood cells, $p<0.5$ was considered significant.
\end{tabular}


Table V. Diagnostic performance of serum PCT levels versus hs-CRP $(n=102)$

\begin{tabular}{|lcccc|}
\hline Parameter & Sensitivity (\%) & Specificity (\%) & $\begin{array}{c}\text { Positive predictive } \\
\text { value (\%) }\end{array}$ & $\begin{array}{c}\text { Negative predictive } \\
\text { value (\%) }\end{array}$ \\
\hline $\mathrm{PCT}>0.5 \mathrm{ng} / \mathrm{ml}$ & 90.6 & 40 & 70.6 & 30.2 \\
\hline $\mathrm{PCT}>0.75 \mathrm{pg} / \mathrm{ml}$ & 81.2 & 17.5 & 83.5 & 17.5 \\
\hline $\mathrm{Hs}-\mathrm{CRP}>3 \mathrm{mg} / \mathrm{l}$ & 78.1 & 25 & 77.1 & 23.9 \\
\hline$P C T-$ procalcitonin & & &
\end{tabular}

$P C T$ - procalcitonin, hs-CRP - high sensitivity C-reactive protein. $P$-value $<0.5$ was considered significant.

A

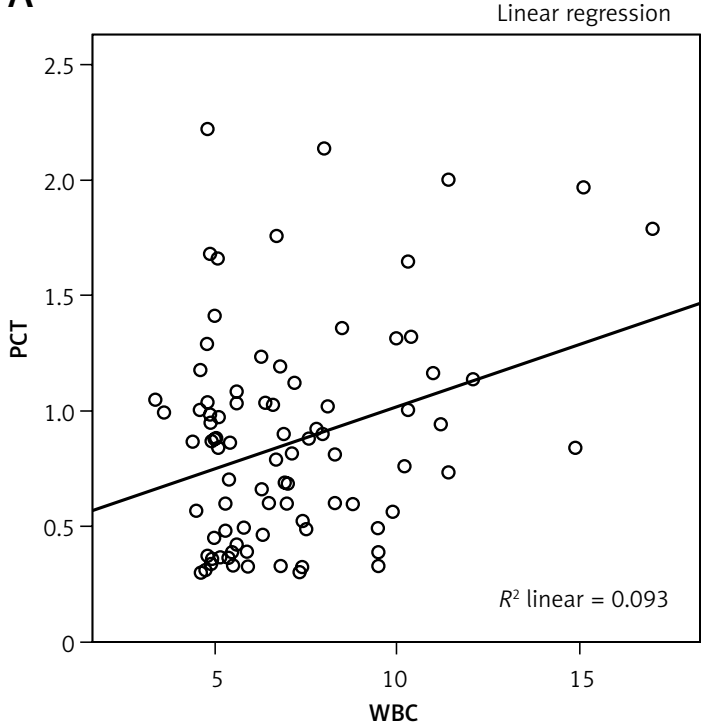

B

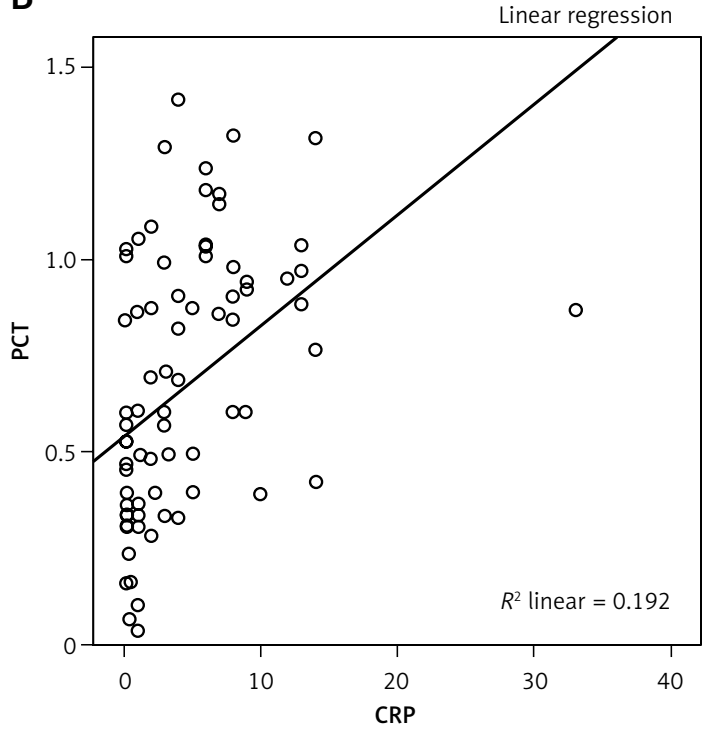

Figure 3. Correlations between procalcitonin (PCT) concentrations, with (A) white blood cells (WBC), and (B) C-reactive protein (CRP). The PCT concentration had a positive correlation with both WBC and CRP

\section{Discussion}

The inflammatory reaction manifests with redness, swelling, pain and fever because of a local reaction against infection or body tissue damage and is replenished with monocytes and neutrophils and inflammatory mediators within thirty to 60 min after the occurrence of inflammation $[35,36]$. The degree of inflammation is managed by measuring acute phase reactant levels in the blood. C-reactive protein is mainly used as an index by clinical diagnosis, but it is not easy to differentiate between the symptoms and signs of infection and inflammation. Procalcitonin values elevate from 3 to $6 \mathrm{~h}$ following a bacterial infection or sepsis, but do not highly elevate in patients with non-infectious inflammation, viral infections, local infections or autoimmune diseases. Hence, PCT helps in the diagnosis of bacterial infections, and has greater sensitivity and specificity than CRP $[37,38]$.

Procalcitonin is a well-known index of bacterial infection, but in cases with multiple injuries, in severe burn cases, and in patients in the early stages of a critical surgery, PCT levels can be increased regardless of infection. Levels can also be elevated during an organ perfusion disorder or after a severe cardiogenic shock $[39,40]$. Furthermore, patients with chronic renal failure have increased PCT values that became lower after $\operatorname{HD}[41,42]$. Thus, the utility of PCT cutoff values for differentiating normal subjects from patients is impractical. In various studies, HD patients without infection had PCT levels slightly higher than normal subjects due to the occurrence of dialysis-related inflammation (e.g. an invasive procedure for HD or peritoneal dialysis (PD)), or an elevation in peripheral blood mononuclear cell counts [43].

A few studies have been done on children to detect the role of procalcitonin as a marker for inflammation and infection. Yavuz et al. [29] reported that CRP and PCT may not be good indicators of reflux nephropathy in vesicoureteral reflux children. Also, the study by Mahyar et al. [39] revealed that serum PCT and IL-1 $\beta$ are not good biologic markers for differentiating acute pyelonephritis from lower urinary tract infection. Conventional inflammatory markers such as erythrocyte sedimentation rate (ESR) and CRP besides the clinical findings are more reliable for the diagnosis of acute pyelonephritis in children. According to Rahimzadeh et al. [26], serum procalcitonin concentration is a sensitive and promising predictor of high-grade vesicoureteral reflux (VUR). Also, Lorton et al. [27] concluded that increase of serum PCT in children with severe 
bacterial infections is mostly massive (10-fold to 1,000 -fold), indicating a low risk for false negative results in these patients. Lastly, the study by Decaluwe et al. [28] revealed that serum levels of PCT are associated with the severity of illness in children with diarrhea-associated hemolytic uremic syndrome.

The present study was performed on the largest group of CKD patients, in which rigorous definitions for a positive bacterial infection were applied, and provides up-to-date insight into PCT and bacterial infections in children on dialysis or with kidney transplantation and an appropriate threshold level. The results of this analysis confirmed comparable diagnostic accuracy for PCT testing in renal impaired children compared with those with normal renal function. Our data show that children with proven infections had higher values for PCT than those without, so it is a powerful biomarker for diagnosis of serious clinical bacterial infections in children with kidney transplantation or on dialysis.

As regards the reference level of serum PCT in normal subjects, at a cutoff of $0.5 \mathrm{ng} / \mathrm{ml}, \mathrm{PCT}$ levels had a sensitivity and specificity of $94.1 \%$ and $87.9 \%$, respectively, with an AUROC of 0.804 . In renal transplant children PCT had a higher sensitivity and specificity, compared to dialysis children. The best cutoff level for the diagnosis of infection for PCT was $0.441 \mathrm{ng} / \mathrm{ml}$ in our study, which is approximately similar to the common level [44]. However, these results are different from those previously published [45].

Previous studies reported that the urine values of PCT were decreased significantly in patients with massive renal impairment. In spite of the decreased renal excretion, the clearance rate of plasma correlated exclusively weakly with renal deterioration, and clinical recommendations based on PCT may not be affected by the stage of renal impairment [46-48]. ROC curve analysis was used in this study to determine the ability of PCT to detect the occurrence of infection. At a cutoff of $0.75 \mathrm{ng} /$ $\mathrm{ml}$, its sensitivity and specificity were $82.4 \%$ and $66.7 \%$, respectively, with an $11.7 \%$ decrease in sensitivity, and was accompanied by a significant drop (of $21.2 \%$ ) in specificity. Moreover, the ROC analysis supports the lower cutoff level. For these results, this study revealed that a serum PCT cutoff of $0.5 \mathrm{ng} / \mathrm{ml}$ is more suitable for the diagnosis of infection in CKD children populations. In a previous study, it was revealed that mean serum PCT decreased following the use of high-flux dialysis, but did not decrease significantly after low-flux dialysis [49]. When using high-flux membranes, serum PCT concentrations should be determined prior to the start of HD. Moreover, PCT levels varied according to the method of dialysis [50].
Other studies in the field of renal transplantation have used a range of cutoffs for PCT, for the diagnosis of infection. These values, from 0.512 to $5.9 \mathrm{mg} / \mathrm{l}[51,52]$, are substantially similar to those detected in this study. This is possibly due to similar criteria used to diagnose infectious episodes, mainly happening in the early posttransplant phase. However, PCT checking for assessing infectious complications in renal transplant receipts must be explained carefully, during antibody therapy [53].

In our study, the number of blood leucocytes significantly increased in children with CKD compared to healthy subjects, and serum hs-CRP significantly increased in children with proven infection compared to the group without proven infection. We did not find a significant difference in AUROC for PCT compared to CRP when comparing the overall performance of the PCT and CRP markers. Though CRP is an extremely sensitive biomarker of inflammation, it cannot usually be applied to differentiate bacterial-related from other inflammations, because it acts likewise and unspecifically to acute phase reactants. We performed a previous study about the role of microinflammation as represented by CRP in VA dysfunction in maintenance pediatric hemodialysis patients, and we concluded that patients with VA dysfunction have significantly higher levels of serum IL-10 and hs-CRP. An altered immune response and microinflammation might contribute to vascular access failure [54]. The diagnostic precision of PCT and CRP is different from those found in intensive care regulation, in which thresholds of $0.6 \mathrm{mg} / \mathrm{l}$ and $7.9 \mathrm{mg} / \mathrm{l}$ for PCT and CRP, respectively, were accompanied with sensitivities of 67.6 and $71.8 \%$ and false positive rates of 39 and $33 \%$, respectively [55]. Several factors differed significantly in the proven group, and among these factors we found positive correlations between each of WBC and CRP with serum PCT. The WBC and CRP are wellknown markers of infection and were positively correlated with PCT [56]. Our data favor the idea of combining PCT and CRP in order to increase the sensitivity and specificity of the tests.

The present study has some limitations. The results represent a single-center experience of a racially homogeneous cohort and may not be generalizable to other populations, and a mixed one, including transplant recipients with immuno-suppressive therapy, but it may be suitable as we are researching the Egyptian pediatric population. While screening and surveillance of CKD in adults, either population-based or targeted at-risk populations, have become important parts of CKD prevention strategies worldwide, the benefit of such programs in children is much more controversial. Tests used for CKD screening in children are usually limited to urinary dipstick protein instead of 
urine albumin/creatinine ratio or creatinine-based calculation of estimated glomerular filtration rate (GFR), as recommended for adults. However, there is substantial variation in the methods used and approaches taken by different countries, and the findings have shown poor reproducibility. There is limited information on the epidemiology of the early stages of CKD in the pediatric population as it is often asymptomatic and therefore under-diagnosed and under-reported. Although some pediatric CKD registries using the National Kidney Foundation's Kidney Disease Outcomes Quality Initiative (K/DOQI) classification are beginning to emerge, only a few reports on the epidemiology of CKD stages 2 to 5 in children are available, and even less is known about low-income countries. For these countries, data are mostly obtained from reports of major tertiary care referral centers, but the validity of these data is variable.

Furthermore, though blood samples were collected during $24 \mathrm{~h}$ of the clinical diagnosis of infection, PCT samples might not be identical and similar, in spite of a lengthy half-life for circulating PCT (up to 25-30 h). Procalcitonin sensitivity and specificity were calculated using the first level detected and not established on a dynamic range. Notwithstanding, our study also has several strengths. There was a healthy normal control group, and rigorous definitions were used for infections (including localized) during a pertinent period of time.

In conclusion, this study has confirmed the previous findings that PCT seem to be activated in circulation of children with established chronic kidney disease. Serum PCT concentrations were significantly increased in CKD children with a bacterial infection, showing the usefulness of serum PCT as an index of infection. Furthermore, this study reveals that a serum PCT cutoff of $0.5 \mathrm{ng} / \mathrm{ml}$ is more appropriate, with good sensitivity and specificity for the diagnosis of infection in CKD children. Procalcitonin can be used as a sensitive biomarker to differentiate systemic bacterial infections from other comorbidities in transplantation of organs.

\section{Acknowledgments}

Our work was supported by the National Research Centre, Cairo, Egypt and the Center of Pediatric Nephrology and Transplantation, Children's Hospital, Cairo University, Cairo, Egypt.

\section{Conflict of interest}

The authors declare no conflict of interest.

\section{References}

1. Coresh J, Selvin E, Stevens LA, et al. Prevalence of chronic kidney disease in the United States. J Am Med Assoc 2007; 298: 2038-47.
2. Nielsen LH, Jensen-Fangel S, Jespersen B, Ostergaard L, Sogaard OS. Risk and prognosis of hospitalization for pneumonia among individuals with and without functioning renal transplants in Denmark: a population-based study. Clin Infect Dis 2012; 55: 679-86.

3. Naqvi SB, Collins AJ. Infectious complications in chronic kidney disease. Adv Chronic Kidney Dis 2006; 13: 199-204.

4. Collins AJ, Foley RN, Herzog C, et al. US Renal Data System. Annual data report. Am J Kidney Dis 2010; 57: A8, e1-526.

5. Vanholder R, Ringoir S, Dhondt A, Hakim R. Phagocytosis in uremic and hemodialysis patients: a prospective and cross sectional study. Kidney Int 1991; 39: 320-7.

6. Vanholder R, Ringoir S. Infectious morbidity and defects of phagocytic function in end-stage renal disease: a review. J Am Soc Nephrol 1993; 3: 1541-54.

7. Lim WH, Kireta S, Leedham E, Russ GR, Coates PT. Uremia impairs monocyte and monocyte-derived dendritic cell function in hemodialysis patients. Kidney Int 2007; 72: 1138-48.

8. Eleftheriadis T, Antoniadi G, Liakopoulos V, Kartsios C, Stefanidis I. Disturbances of acquired immunity in hemodialysis patients. Semin Dial 2007; 20: 440-51.

9. Sarnak MJ, Jaber BL. Pulmonary infectious mortality among patients with end-stage renal disease. Chest 2001; 120: 1883-7.

10. Sarnak MJ, Jaber BL. Mortality caused by sepsis in patients with end-stage renal disease compared with the general population. Kidney Int 2000; 58: 1758-64.

11. Strijack B, Mojica J, Sood M, et al. Outcomes of chronic dialysis patients admitted to the intensive care unit. J Am Soc Nephrol 2009; 20: 2441-7.

12. Hutchison CA, Crowe AV, Stevens PE, Harrison DA, Lipkin GW. Case mix, outcome and activity for patients admitted to intensive care units requiring chronic renal dialysis: a secondary analysis of the ICNARC Case Mix Programme Database. Crit Care 2007; 11: R50.

13. Manhes G, Heng AE, Aublet-Cuvelier B, Gazuy N, Deteix P, Souweine B. Clinical features and outcome of chronic dialysis patients admitted to an intensive care unit. Nephrol Dial Transplant 2005; 20: 1127-33.

14. Bell M, Granath F, Schon S, Lofberg E, Ekbom A, Martling CR. End-stage renal disease patients on renal replacement therapy in the intensive care unit: short- and long-term outcome. Crit Care Med 2008; 36: 2773-8.

15. Carrigan SD, Scott G, Tabrizian M. Toward resolving the challenges of sepsis diagnosis. Clin Chem 2004; 50: 1301-4.

16. Jaimes F, Arango C, Ruiz G, et al. Predicting bacteremia at the bedside. Clin Infect Dis 2004; 38: 357-62.

17. Bone RC, Balk RA, Cerra FB, et al. Definitions for sepsis and organ failure and guidelines for the use of innovative therapies in sepsis. The ACCP/SCCM Consensus Conference Committee. American College of Chest Physicians/Society of Critical Care Medicine. Chest 1992; 101: 1644-55.

18. Reynvoet E, Vandijck DM, Blot SI, et al. Epidemiology of infection in critically ill patients with acute renal failure. Crit Care Med 2009; 37: 2203-9.

19. Bossink A, Groeneveld J, Lambertus G. Prediction of microbial infection and mortality in medical patients with fever: plasma procalcitonin, neutrophilic elastase-alpha-antitrypsin and lactoferrin compared with clinical variables. Clin Infect Dis 1999; 29: 398-407.

20. Lu XL, Xiao ZH, Yang MY, Zhu YM. Diagnostic value of serum procalcitonin in patients with chronic renal insufficiency: a systematic review and meta-analysis. Nephrol Dial Transplant 2013; 28: 122-9. 
21. Tang H, Huang T, Jing J, Shen H, Cui W. Effect of procalcitonin-guided treatment in patients with infections: a systematic review and meta-analysis. Infection 2009; 37: 497-507.

22. Jones AE, Fiechtl JF, Brown MD, Ballew JJ, Kline JA. Procalcitonin test in the diagnosis of bacteremia: a meta-analysis. Ann Emerg Med 2007; 50: 34-41.

23. Prkno A, Wacker C, Brunkhorst FM, Schlattmann P. Procalcitonin-guided therapy in intensive care unit patients with severe sepsis and septic shock: a systematic review and meta-analysis. Crit Care 2013; 17: R291.

24. Guz G, Colak B, Hizel K, et al. Procalcitonin and conventional markers of inflammation in peritoneal dialysis patients and peritonitis. Perit Dial Int 2006; 26: 240-8.

25. Pfafflin A, Schleicher E. Inflammation markers in pointof-care testing (POCT). Anal Bioanal Chem 2009; 393: 1473-80.

26. Rahimzadeh N, Otukesh H, Hoseini R, Shadani S, Hooman N. Serum procalcitonin level for prediction of high-grade vesicoureteral reflux in urinary tract infection. Iran J Kidney Dis 2014; 8: 105-8.

27. Lorton F, Veinberg F, lelsch D, Deschênes G, Bensman A, Ulinski T. Procalcitonin serum levels in children undergoing chronic haemodialysis. Pediatr Nephrol 2007; 22: 430-5.

28. Decaluwe $\mathrm{H}$, Harrison LM, Mariscalco MM, et al. Procalcitonin in children with Escherichia coli 0157:H7 associated hemolytic uremic syndrome. Pediatr Res 2006; 59 : 579-83.

29. Yavuz S, Anarat A, Bayazıt AK. Interleukin-18, CRP and procalcitonin levels in vesicoureteral reflux and reflux nephropathy. Ren Fail 2013; 35: 1319-22.

30. Levy MM, Fink MP, Marshall JC, et al. 2001 SCCM/ ESICM/ACCP/ATS/SIS international sepsis definitions conference. Intensive Care Med 2003; 29: 530-8.

31. Woodhead M, Blasi F, Ewig S, et al. Guidelines for the management of adult lower respiratory tract infections. Clin Microbiol Infect 2011; 17 (Suppl 6): E1-59.

32. Gupta K, Hooton TM, Naber KG, et al. International clinical practice guidelines for the treatment of acute uncomplicated cystitis and pyelonephritis in women: a 2010 update by the Infectious Diseases Society of America and the European Society for Microbiology and Infectious Diseases. Clin Infect Dis 2011; 52: e103-20.

33. Farthing $M$, Salam M, Lindberg G, et al. World Gastroenterology Organisation global guidelines. Acute diarrhea in adults and children: a global perspective. 2012. http://www.worldgastroenterology.org/assets/export/ userfiles/Acute\%20Diarrhea_long_FINAL_120604.pdf

34. Hanley JA, McNeil BJ. A method of comparing the areas under receiver operating characteristic curves derived from the same cases. Radiology 1983; 148: 839-43.

35. Mitaka C. Clinical laboratory differentiation of infectious versus non-infectious systemic inflammatory response syndrome. Clin Chim Acta 2005; 351: 17-29.

36. Grace E, Turner RM. Use of procalcitonin in patients with various degrees of chronic kidney disease including renal replacement therapy. Clin Infect Dis 2014; 59: 1761-7.

37. Hur M, Moon HW, Yun YM, Kim KH, Kim HS, Lee KM. Comparison of diagnostic utility between procalcitonin and $\mathrm{C}$-reactive protein for the patients with blood culture-positive sepsis. Korean J Lab Med 2009; 29: 529-35.

38. Mitaka C. Clinical laboratory differentiation of infectious versus non-infectious systemic inflammatory response syndrome. Clin Chim Acta 2005; 351: 17-29.

39. Mahyar A, Ayazi P, Ahmadi R, et al. Are serum procalcitonin and interleukin-1 beta suitable markers for diag- nosis of acute pyelonephritis in children? Prague Med Rep 2014; 115: 16-23.

40. Kuse ER, Langefeld I, Jaeger K, Kulpmann WR. Procalcitonin in fever of unknown origin after liver transplantation: a variable to differentiate acute rejection from infection. Crit Care Med 2000; 28: 555-9.

41. Lee WS, Kang DW, Back JH, Kim HL, Chung JH, Shin BC. Cutoff value of serum procalcitonin as a diagnostic biomarker of infection in end-stage renal disease patients. Korean J Intern Med 2015; 30: 198-204.

42. Trimarchi H, Dicugno M, Muryan A, et al. Pro-calcitonin and inflammation in chronic hemodialysis. Medicina (B Aires) 2013; 73: 411-6.

43. Herget-Rosenthal S, Klein T, Marggraf G, et al. Modulation and source of procalcitonin in reduced renal function and renal replacement therapy. Scand J Immunol 2005; 61: 180-6.

44. Dumea R, Siriopol D, Hogas S, Mititiuc I, Covic A. Procalcitonin: diagnostic value in systemic infections in chronic kidney disease or renal transplant patients. Int Urol Nephrol 2014; 46: 461-8.

45. Palomar-Fontanet R, Lavin-Gómez BA, Quintanar-Lartundo JA, et al. Markers of inflammation before and during peritoneal dialysis. Adv Perit Dial 2011; 27: 28-32.

46. Meisner M, Huttemann E, Lohs T, Kasakov L, Reinhart K. Elimination of procalcitonin and plasma concentrations during continuous venovenous haemodiafiltration in septic patients. Eur J Anaesthesiol 2000; 17: 665-71.

47. Meisner M, Hüttemann E, Lohs T, Schmidt J, Huller M, Reinhart K. Plasma concentrations and clearance of procalcitonin during continuous venovenous hemofiltration in septic patients. Shock 2001; 15: 171-5.

48. Meisner M, Lohs T, Huettemann E, Schmidt J, Hueller M, Reinhart K. The plasma elimination rate and urinary secretion of procalcitonin in patients with normal and impaired renal function. Eur J Anaesthesiol 2001; 18: 79-87.

49. Montagnana M, Lippi G, Tessitore N, et al. Procalcitonin values after dialysis is closely related to type of dialysis membrane. Scand J Clin Lab Invest 2009; 69: 703-7.

50. Rosenthal SH, Marggraf G, Pietruck F, et al. Procalcitonin for accurate detection of infection in haemodialysis. Nephrol Dial Transplant 2001; 16: 975-9.

51. Eberhard OK, Langefeld I. Procalcitonin in the early phase after renal transplantation - will it add to diagnostic accuracy? Clin Transpl 1998; 12: 206-11.

52. Hammer S, Meisner F, Dirschedl P, Fraunberger P, Meiser B. Procalcitonin for differential diagnosis of graft rejection and infection in patients with heart and/or lung grafts. Intensive Care Med 2000; 26: S182-6.

53. Sabat R, Hoflich C, Docke WD, et al. Massive elevation of procalcitonin plasma levels in the absence of infection in kidney transplant patients treated with pan-T-cell antibodies. Intensive Care Med 2001; 27: 987-91.

54. Elshamaa MF, Sabry S, Galal A, et al. Serum interleukin-10 levels and microinflammation in vascular access failure in Egyptian children on hemodialysis. J Clin Basic Cardiol 2009; 12: 18-23.

55. Cooper D, Sharples L, Cornelissen J, Wallwork J, Alexander G, Trull A. Comparison between procalcitonin, serum amyloid $\mathrm{A}$, and $\mathrm{C}$-reactive protein as markers of serious bacterial and fungal infections after solid organ transplantation. Transpl Proc 2001; 33: 1808-10.

56. Lee SJ, Jung YC, Jeon DO, et al. High serum C-reactive protein level predicts mortality in patients with stage 3 chronic kidney disease or higher and diabetic foot infections. Kidney Res Clin Pract 2013; 32: 171-6. 